Supplement of The Cryosphere, 12, 2401-2411, 2018

https://doi.org/10.5194/tc-12-2401-2018-supplement

(C) Author(s) 2018. This work is distributed under

the Creative Commons Attribution 4.0 License.

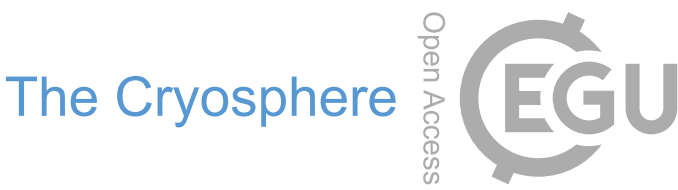

(c) (1)

Supplement of

\title{
Modelled fracture and calving on the Totten Ice Shelf
}

Sue Cook et al.

Correspondence to: Sue Cook (sue.cook@utas.edu.au)

The copyright of individual parts of the supplement might differ from the CC BY 4.0 License. 


\section{Supplementary Material}

\section{Observed iceberg sizes}

To obtain the current iceberg size distribution for the Totten Ice Shelf, icebergs were manually digitised from three Landsat 7 images acquired on 23/11/2009, 26/11/2010 and 29/11/2011. The dataset consists of 370 icebergs with areas between 0.001 and $5.8 \mathrm{~km}^{2}$. The breakdown of the observation number of icebergs by year is 83 (2009), 148 (2010), 139 (2011).

The choice of three images from November was motivated by the availability of high resolution optical imagery, with low cloud cover and low presence of sea ice - icebergs are more easily delineated against a dark ocean background than white sea ice. The three years selected covered periods of both low and high iceberg calving. The period Aug 2009 - Aug 2010 produced a rate of $0.05 \mathrm{~km}^{2} /$ day, while the period Aug 2010 - Aug 2011 produced icebergs at a rate of $0.44 \mathrm{~km}^{2} /$ day (personal communication, Dr. Liu Yan, Beijing Normal University).

Despite this difference in calving behaviour, the size distribution of icebergs was similar in all three images digitised. Each of the three images produces a roughly $-3 / 2$ slope at large iceberg sizes. At smaller sizes the frequency of observed icebergs is lower than expected this is because of a number of factors; difficulty in optically resolving small icebergs, difficulty in distinguishing smaller icebergs from sea ice and fatigue of the digitiser. The similarity in the three profiles leads us to conclude that the frequency size distribution is a robust test of the fracture model.

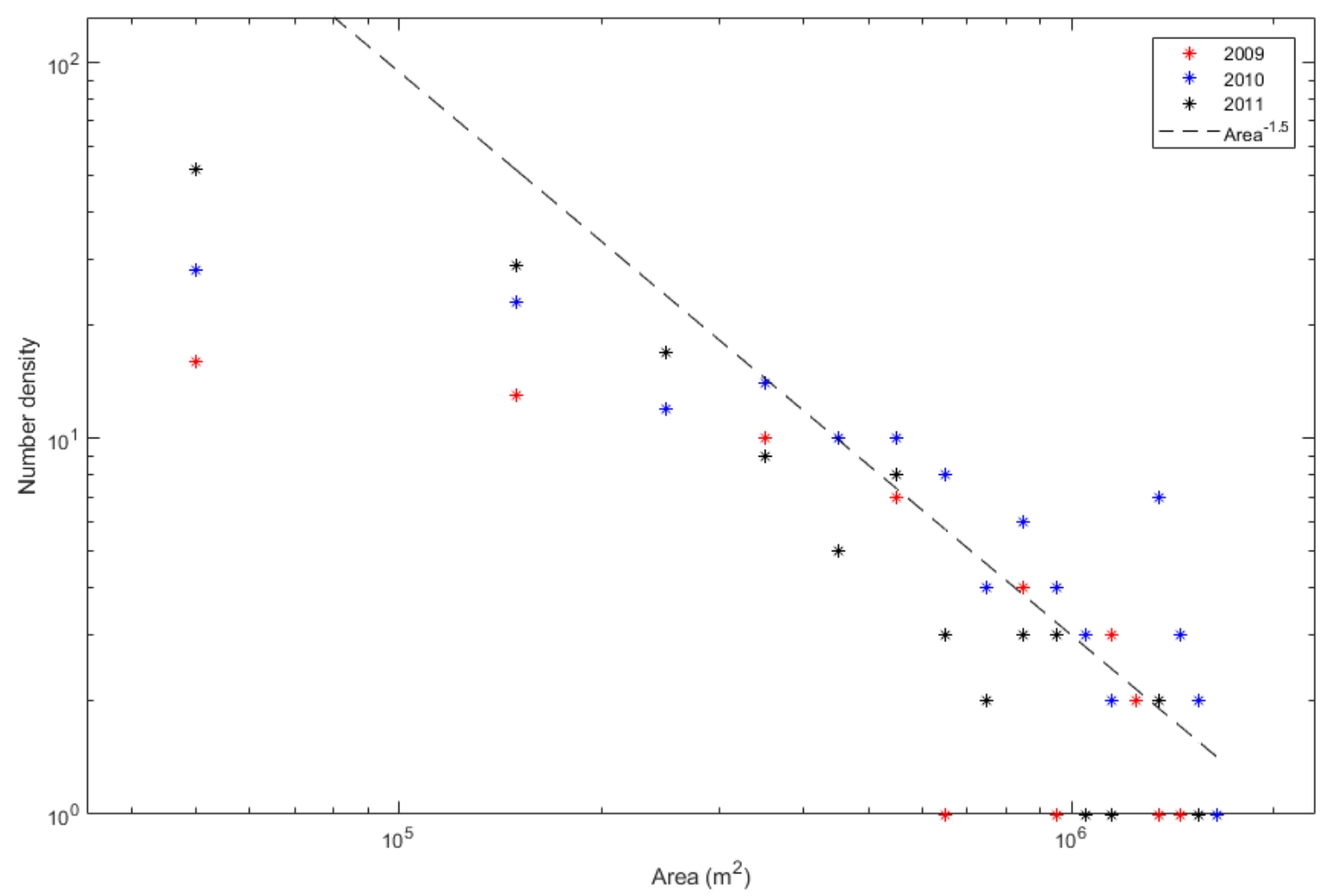

Supplementary Figure 1: Iceberg size frequency distribution by year. Red, blue and black stars represent frequency of iceberg sizes in years 2009, 2010 and 2011 respectively. Dashed black line shows the theoretical size distribution with a slope of $-3 / 2$. 


\section{Fracture orientations}

The other method used for examining the performance of the HiDEM model is comparing the modelled and observed fracture patterns on the ice shelf. This can be done visually in Figure 2, where the model exhibits a large number of fractures perpendicular to the calving front, but does not reproduce the across-flow fractures which can be observed in satellite imagery. Since these across-flow features can be observed many kilometres upstream of the calving front they appear to advect into the model domain and are not produced locally.

More information on the observed and modelled fractures can be extracted by measuring their orientations. To do this, fractures from both the HiDEM model and a satellite image from Sentinel 1 were manually digitised. Each identified fracture was split into segments, and the angle of each segment calculated. The distribution of orientations is shown in Supplementary Figure 2. Angles are referenced to true north.

The across-flow fractures have an azimuth of roughly $40^{\circ}$ and are extremely prominent in the observed data, but show a much reduced frequency in the modelled distribution. Fractures near the calving front, which typically form perpendicular to the calving front, cover a much larger range of orientations, due to the complex shape of the calving front. These are the dominant fractures in the modelled distribution, but have a lower relative frequency in the observed distribution.

Fracture length and spacing have not been chosen as a method of validating model output because of the difficulty in reliably identifying fracture extent in satellite imagery. This region of East Antarctica experiences extremely high snowfall, which acts to mask surface crevasses. This means that any observation of fracture length will be unreliable. Similarly, smaller fractures may be completely obscured by high snowfall, leading to high uncertainty in observed fracture spacing.
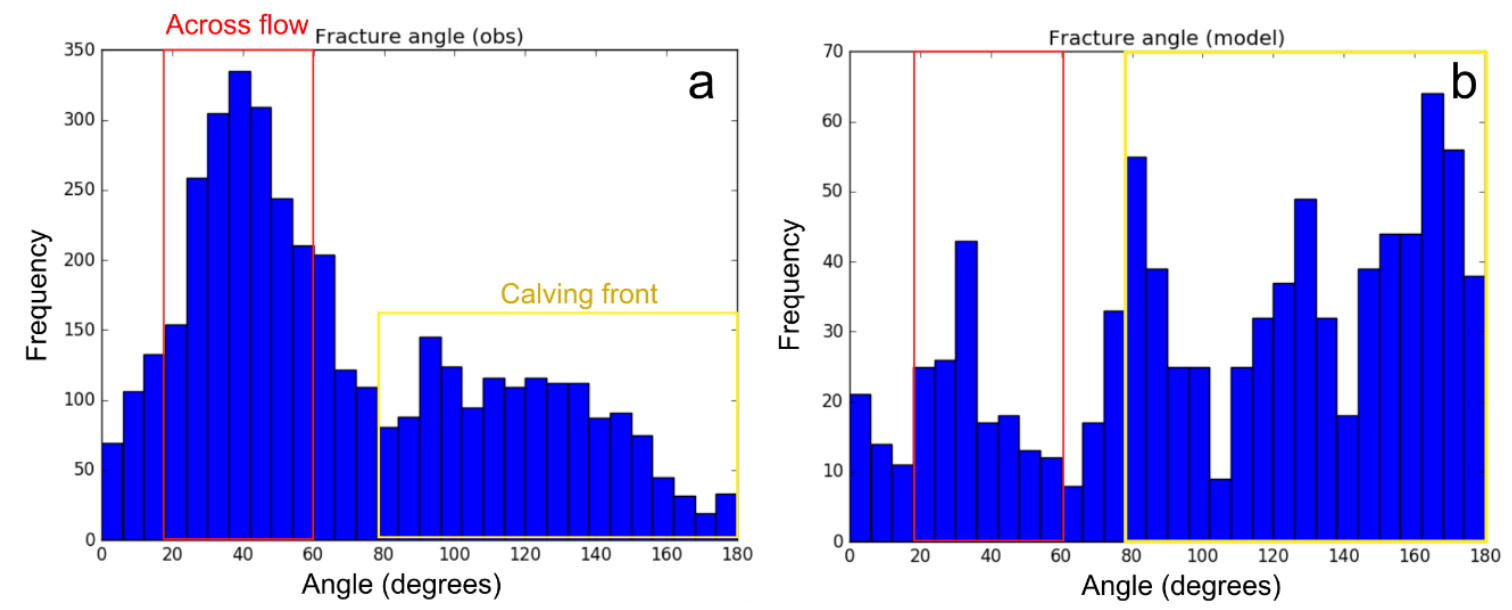

Supplementary Figure 2: Observed and modelled fracture orientations a. In the observed fractures the across flow features are the most frequent category (red box) b. In the model output, the frequency of across flow features is significantly reduced. Angles are referenced to true north. 